\title{
Sensitivity Analysis of the Dust-Generation Algorithm in ADAM3 by Incorporating Surface-Wetness Effects
}

\author{
Yunkyu Lim, Misun Kang *(1) and Jinwon Kim (1) \\ National Institute of Meteorological Sciences, 33 Seohobuk-ro, Seogwipo-si 63568, Jeju-do, Korea; \\ imyunkyu@korea.kr (Y.L.); jkim@atmos.ucla.edu (J.K.) \\ * Correspondence: misun0106@korea.kr; Tel.: +82-64-780-6588
}

check for updates

Citation: Lim, Y.; Kang, M.; Kim, J.

Sensitivity Analysis of the

Dust-Generation Algorithm in

ADAM3 by Incorporating

Surface-Wetness Effects. Atmosphere

2021, 12, 872. https://doi.org/

10.3390/atmos 12070872

Academic Editor: Thomas Gill

Received: 30 April 2021

Accepted: 30 June 2021

Published: 5 July 2021

Publisher's Note: MDPI stays neutral with regard to jurisdictional claims in published maps and institutional affiliations.

Copyright: (c) 2021 by the authors. Licensee MDPI, Basel, Switzerland. This article is an open access article distributed under the terms and conditions of the Creative Commons Attribution (CC BY) license (https:// creativecommons.org/licenses/by/ $4.0 /)$.
Abstract: This study examined the surface-wetness effects in calculating dust generation in source regions, using Asian dust aerosol model version 3 (ADAM3; the control run; CNTL). Model sensitivity experiment was conducted in such a way that the dust generation in CNTL is compared against three ADAM3 versions with various surface-wetness effect schemes. The dust-generation algorithm in ADAM_RAIN utilizes precipitation, while the scheme in ADAM3_SM1 and ADAM3_SM2 employs soil water content to account for the surface-wetness effects on dust generation. Each run was evaluated for the spring (March-May) of 2020. ADAM3_SM1 shows the best performance for the dust source region in East Asia based on the root-mean-square error and the skill score, followed by ADAM3_SM2 and ADAM3_RAIN. Particularly, incorporation of the surface-wetness effects improves dust generation mostly in wet cases rather than dry cases. The three surface-wetness-effect runs reduce dust generation in the source regions compared to CNTL; hence, the inclusion of surfacewetness effects improves dust generation in the regions where CNTL overestimates dust generation.

Keywords: ADAM3; regional modeling; surface-wetness effects; precipitation; soil water content; dust; dust generation

\section{Introduction}

In Northeast Asia, air-pollution events caused by high concentrations of particulate matter (PM) occur frequently due to recent increases in industrial activities and population [1,2]. Lee et al. [3] estimated the contribution of the transboundary PM transport from China to the concentration of PM of diameters less or equal to $10 \mu \mathrm{m}\left(\mathrm{PM}_{10}\right)$ in South Korea is approximately $40-50 \%$. Oh et al. [4] also showed that the transboundary pollutant transport from China plays a major role in the occurrence of multi-day severe air-pollution episodes in Seoul, South Korea. Both anthropogenic air pollutants and dust in East Asia cause high $\mathrm{PM}_{10}$ concentration events over Korea. Dust in East Asia is largely composed of dry soil particles and exerts great social and economic impacts on East Asia [5-7].

The Korea Meteorological Administration (KMA), China Meteorological Administration (CMA), and Japan Meteorological Agency (JMA) have developed and operated various dust prediction models to monitor and predict dust events in East Asia. Collaborative research is also ongoing to increase the prediction performance of dust models through the Asian node of the Sand and Dust Storm Warning Advisory and Assessment System (SDS-WAS) of the World Meteorological Organization [8]. The Asian node of SDS-WAS has intercompared operational dust models, including the KMA Asian Dust Aerosol Model (ADAM) [9-12], the JMA Model of Aerosol Species in the Global Atmosphere (MASINGAR) [13], and the CMA Chinese Unified Atmospheric Chemistry Environment for Dust (CUACE/Dust) [14,15], in forecasting the dust events in East Asia.

Dusts in East Asia originate mainly in the arid regions in Mongolia, the Gobi Desert, Manchuria, the Inner Mongolia Plateau, the Loess Plateau, and Northwestern China [16,17]. Among these source regions, South Korea is primarily affected by the Gobi Desert, the Inner Mongolia plateau, and Manchuria [18-21]. Surface conditions, such as soil moisture, 
play an important role in both the location of the source regions and the intensity of dust generation [22,23]. If a low-pressure system in the source region accompanies precipitation, surface soil moisture increases to suppress dust generation. Because of this, several studies introduced parameterizations for calculating the dust-uplift process in terms of wind speed, soil water content, and vegetation cover [24].

Recent evaluation studies showed that Asian dust aerosol model version 3 (ADAM3) often tends to overestimate dust generation during the period of precipitation. In ADAM3, dust generation in East Asia is determined based on $10 \mathrm{~m}$ wind speeds and relative humidity thresholds; the algorithm also assumes that no dust in East Asia is generated if the 3-h cumulative precipitation prior to the forecast time exceeds $0.2 \mathrm{~mm}[10,11]$. A series of model improvement projects [25] suggested that ADAM3 needs an improved representation of the effect of precipitation (or soil moisture) on dust generation in order to alleviate biases over the source regions. In addition, direct consideration of the precipitation effects on land surfaces instead of indirectly through relative humidity, is necessary to improve dust generation in ADAM3.

This study aims to improve the dust-generation algorithm in ADAM3 by incorporating surface-wetness effects on dust generation. This study will improve our understanding of the effects of precipitation and land-surface processes in the source regions on dust predictions for South Korea and East Asia.

\section{Materials and Methods}

\subsection{Asian Dust Aerosol Model Version 3 (ADAM3)}

The KMA operated the ADAM model for forecasting dust events in South Korea from 2007. The ADAM model was developed by incorporating the dust-generation algorithm [9-12] into the Community Multiscale Air Quality model version 4.7.1 (CMAQ v4.7.1), which is a chemical transport model developed by the United States Environmental Protection Agency. Recently, the ADAM3 was developed by incorporating anthropogenic sources of particulate matter (PM), a dust generation reduction factor [26], the assimilation of PM data from surface stations, and satellite-observed aerosol optical-depth data. Ryoo et al. [12] showed that the performance of ADAM3 was markedly improved compared with the second-generation ADAM. The hit rate, threat score and the probability of detection in ADAM3 showed $94.9 \%, 32.0 \%$, and $48.5 \%$, respectively. However, ADAM3 substantially underestimated dust days in Northwestern China.

The meteorological fields for running ADAM simulations are obtained from the KMA global forecasting model, currently the Unified Model of the United Kingdom Met Office [27]. The ADAM prediction domain covers the East Asia region centered at $126^{\circ} \mathrm{E}$, $38^{\circ} \mathrm{N}$ (Figure 1) with a $340 \times 220$ grid nest of $25 \mathrm{~km}$ resolutions and irregularly spaced 49 sigma levels from the surface to the $100 \mathrm{hPa}$ level. In ADAM3, the anthropogenic emissions within South Korea are calculated by using the Sparse Matrix Operator of Kernel Emissions version 3.7 (SMOKE v3.7) with input data from the Clean Air Policy Support System 2013 (CAPSS 2013) produced by the National Institute of Environmental Research of South Korea, whereas the anthropogenic emissions outside South Korea are obtained from the Model Inter Comparison Study for Asia 2010 (MICS-Asia 2010). The natural emissions are produced by using the Model of Emissions of Gases and Aerosols from Nature version 2.0.4 (MEGAN v2.0.4) [28]. 


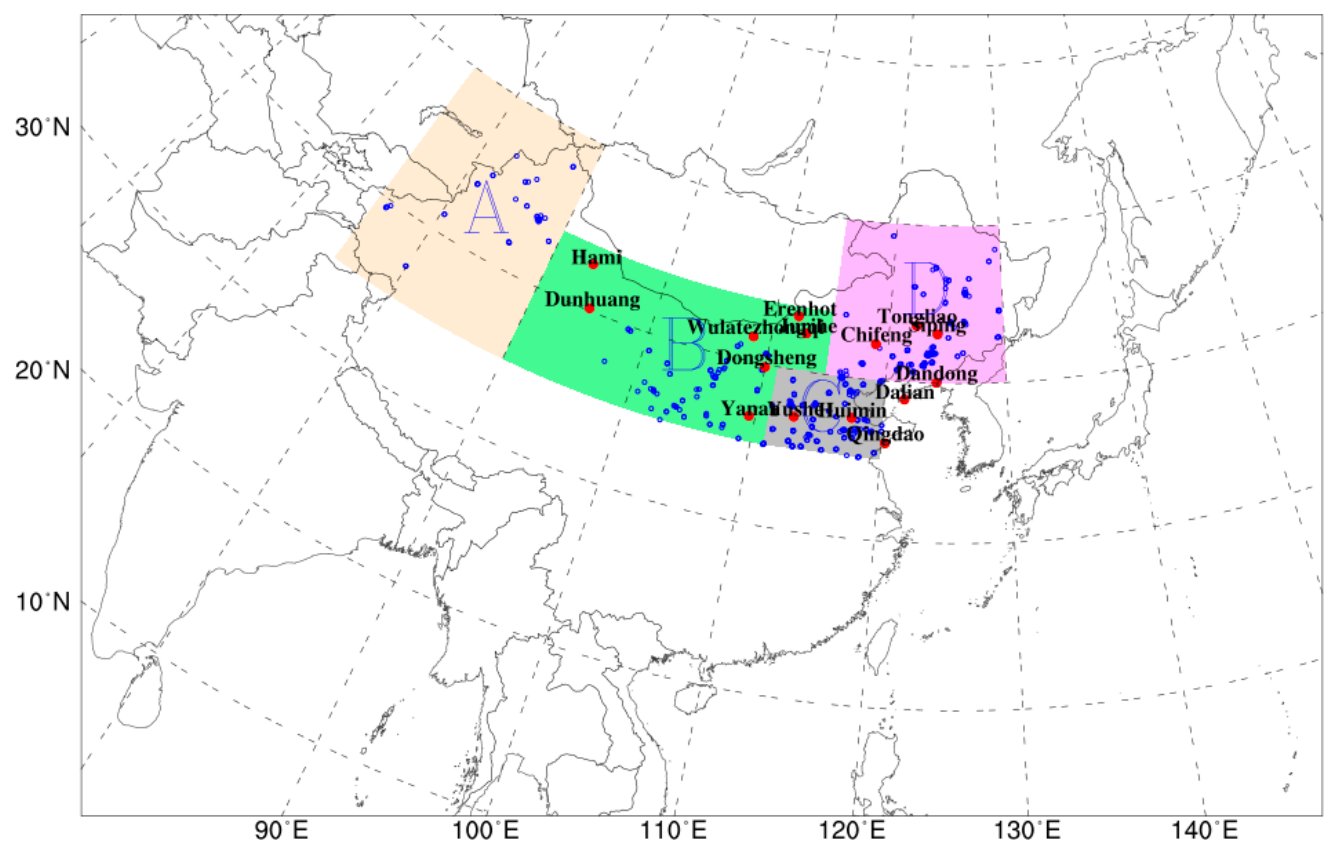

Figure 1. Distribution of the dust source regions in East Asia (Region $A=$ Northwestern China, Region $\mathrm{B}=$ Inner Mongolia, Region C = four provinces near the Huabei Plain, and Region D = Manchuria) and location of $\mathrm{PM}_{10}$ observation sites. The blue circles are observation sites of $\mathrm{PM}_{10}$ mass concentrations operated by the Ministry of Environmental Protection of China, and the red circles are KMA-CMA joint monitoring stations and GTS sites.

Dust generation in the ADAM3 dust algorithm is determined by the threshold wind speed, relative humidity, temperature, and precipitation, which vary by time and region. In order to represent the surface-wetness effects on dust generation, ADAM3 uses relative humidity for the threshold conditions in calculating dust generation. Dust generation amounts are proportional to the fourth power of the friction velocity and are reduced according to the fraction of vegetated surfaces as in Equation (1) below:

$$
H_{A D A M 3}=\sum_{i=1}^{n}\left(1-f_{i} R_{i}\right) \times \alpha \times u_{*}^{4}, \text { if } U_{10} \geq U_{10 t} \text { and } R H_{10} \leq R H_{10 t},
$$

where $H_{A D A M 3}$ is the dust flux at the surface, $u_{*}$ is the friction velocity, $U_{10}$ is the $10 \mathrm{~m}$ wind speed, $U_{10 t}$ is the threshold for the $10 \mathrm{~m}$ wind speed, $R H_{10}$ is the $10 \mathrm{~m}$ relative humidity, and $\mathrm{RH}_{10 t}$ is the threshold for the $10 \mathrm{~m}$ relative humidity. Details on $R H_{10 t}$ can be found in Table 1 of Park and In [9]. In addition, $f_{i}$ is the fractional coverage of the $i$-type of vegetation in a dust source grid, $R_{i}$ the reduction factor by the $i$-type vegetation. Moreover, $\alpha$ is a constant obtained empirically in a sensitivity experiment in which multiple simulations were performed by using a range of values to find the one that minimizes the errors in simulating dust concentrations. Detailed information for ADAM3 can be found in Section 2.1 of Ryoo et al. [12]. 
Table 1. RMSE for the CNTL, ADAM3_RAIN, ADAM3_SM1, and ADAM3_SM2 runs and SS of three compared runs (ADAM3_RAIN, ADAM3_SM1, and ADAM3_SM2) with reference of CNTL. The evaluation period was set for the spring season from March to May 2020. All represents total cases for Regions B, C, and D, whereas wet and dry denote precipitation and non-precipitation cases for Regions B and C, respectively. The total number of forecasts (n) is 1,102,528.

\begin{tabular}{cccccccc}
\hline \multirow{2}{*}{ Case } & CNTL & \multicolumn{2}{c}{ ADAM3_RAIN } & \multicolumn{2}{c}{ ADAM3_SM1 } & \multicolumn{2}{c}{ ADAM3_SM2 } \\
\cline { 2 - 7 } & RMSE & RMSE & SS & RMSE & SS & RMSE & SS \\
\hline All & 90.22 & 86.43 & 4.61 & 79.53 & 12.51 & 80.36 & 11.40 \\
Wet & 73.65 & 68.29 & 7.08 & 60.42 & 17.53 & 61.71 & 15.76 \\
Dry & 64.19 & 62.50 & 2.65 & 58.90 & 8.15 & 59.91 & 6.63 \\
\hline
\end{tabular}

\subsection{Study Area and Observation}

The study area (Figure 1) covers the dust source regions in Northwestern China (Region A), Inner Mongolia (Region B), four provinces near the Huabei Plain (Region C), and Manchuria (Region D) according to the study area of Hong et al. [25]. Region A was excluded from the evaluation because Ryoo et al. [12] and Hong et al. [25] showed that ADAM3 substantially underestimates the dust events in this region.

To analyze the $\mathrm{PM}_{10}$ frequency, the 3-hourly $\mathrm{PM}_{10}$ mass concentration is obtained from 15 KMA-CMA joint monitoring stations (Figure 1 red circles). Moreover, meteorological information such as precipitation and wind speed is obtained from 15 Global Telecommunication System (GTS) sites for classification of precipitation and non-precipitation cases and the definition of dust generation on the frequency analysis of $\mathrm{PM}_{10}$. The KMA-CMA joint monitoring stations are located at the GTS sites (Figure 1 red circles). The analysis period is from 2004 to 2019. Moreover, hourly $\mathrm{PM}_{10}$ mass concentration data from 1498 Ministry of Environmental Protection (MEP) sites in China from March to May 2020 were used to evaluate the simulated $\mathrm{PM}_{10}$ mass concentration. The performance of all runs was evaluated by using the hourly $\mathrm{PM}_{10}$ mass concentration data from $1498 \mathrm{MEP}$ sites for Regions B, C, and D. The observation sites are described in Figure 1.

\subsection{Evaluation}

The evaluation period is the 2020 spring (March-May) season when dust is most prominent in South Korea [29]. The simulations generated 72-h predictions starting at every 00 UTC. These predictions were evaluated for the $25-48$-h period of each forecast cycle to exclude the effect of data assimilation in the initial data.

The root-mean-square error (RMSE), skill score (SS), and mean bias error (MBE) were used as evaluation criteria. The RMSE can be calculated by using the following equation:

$$
\text { RMSE }=\sqrt{\frac{\sum_{i=1}^{n}\left(F_{i}-O_{i}\right)^{2}}{n}},
$$

where $F_{i}$ and $O_{i}$ indicate the $i$ th predicted and observed $\mathrm{PM}_{10}$ mass concentrations, respectively, and $\mathrm{n}$ indicates the total number of cases during the evaluation period.

The SS [30] for all experimental runs except ADAM3 can be calculated by using the following equation:

$$
\mathrm{SS}=\left(1-\frac{\mathrm{RMSE}}{\mathrm{RMSE}_{\mathrm{ref}}}\right) \times 100,
$$

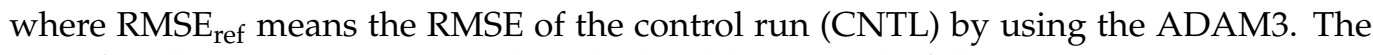
MBE for all experiment runs can be calculated by using the following equation:

$$
\mathrm{MBE}=\frac{\sum_{i=1}^{n}\left(F_{i}-O_{i}\right)}{n} .
$$




\section{Experimental Design}

Dust generation from four ADAM3 simulations with different schemes for surfacewetness effects on dust generation (i.e., CNTL, ADAM3_RAIN, ADAM3_SM1, and ADAM3_SM2) are intercompared and evaluated against observed $\mathrm{PM}_{10}$ mass concentrations. The algorithm in ADAM_RAIN uses precipitation over a specified period prior to the dust generation calculation to account for surface-wetness effects in calculating dust generation. The two runs ADAM3_SM1 and ADAM3_SM2 represent the surface-wetness effects on dust generation more directly by using the parameterizations of Tanaka and Chiba [13] and Gong et al. [14], respectively, which use soil water content terms in calculating dust generation fluxes. More details of the dust-generation control schemes in ADAM3_RAIN, ADAM3_SM1, and ADAM3_SM2 are presented in the following subsections. Moreover, a summary of experimental design is shown in Table 2.

Table 2. Summary of experimental design.

\begin{tabular}{lcr}
\hline Experiment Run & $\begin{array}{c}\text { Surface-Wetness } \\
\text { Effects Term }\end{array}$ & Description \\
\hline CNTL & $\mathrm{RH}_{10}$ & $\begin{array}{c}\text { Relative humidity is used for threshold } \\
\text { conditions to represent the surface-wetness } \\
\text { effects on dust generation }\end{array}$ \\
\hline ADAM3_RAIN & $\mathrm{RH}_{10}$, PRain & $\begin{array}{c}\text { Precipitation over the 3-h period from } 6 \text { to } 3 \mathrm{~h} \\
\text { prior to dust generation calculation }(P R \text { Rin }) \text { was } \\
\text { added to the dust generation term in CNTL to } \\
\text { represent the surface-wetness effects }\end{array}$ \\
\hline ADAM3_SM1 & $\left(1-\left(\frac{u_{* t}}{u_{*}}\right)^{2}\right)$ & $\begin{array}{c}\text { The adjustment factor term related to soil } \\
\text { moisture was added to the dust generation term } \\
\text { in CNTL to represent the surface-wetness effects }\end{array}$ \\
\hline ADAM3_SM2 & $\left(1+\frac{u_{* t}}{u_{*}}\right)\left(1-\left(\frac{u_{* t}}{u_{*}}\right)^{2}\right)$ &
\end{tabular}

\subsection{ADAM3_RAIN}

ADAM3_RAIN employs the accumulated precipitation (PRain) over the 3-h period from 6 to $3 \mathrm{~h}$ prior to the dust generation calculation. The adjustment factor, $P R f$, is formulated in terms of PRain as follows:

$$
P R f=0.1 \times \operatorname{EXP}(-0.9 \times \text { PRain }), \text { if PRain }>0,
$$

where $P R f$ varies from approximately 0.1 to 0.0 as PRain increases (Figure 2a); $P R f$ is 1 when there is no rain (PRain $=0$ ). The dust generation $H_{A D A M 3} \_$RAIN in ADAM3_RAIN incorporates $P R f$ as follows:

$$
H_{A D A M 3_{-} R A I N}=\sum_{i=1}^{n}\left(1-f_{i} R_{i}\right) \times P R f \times \alpha \times u_{*}^{4}, \text { if } U_{10} \geq U_{10 t} \text { and } R H_{10} \leq R H_{10 t} .
$$

The condition for dust generation in ADAM3_RAIN $\left(U_{10} \geq U_{10 t}\right.$ and $\left.R H_{10} \leq R H_{10 t}\right)$ is the same as in CNTL. However, the dust generation decreases as the precipitation over the 3-h period from 6 to $3 \mathrm{~h}$ prior to the calculation increases. 

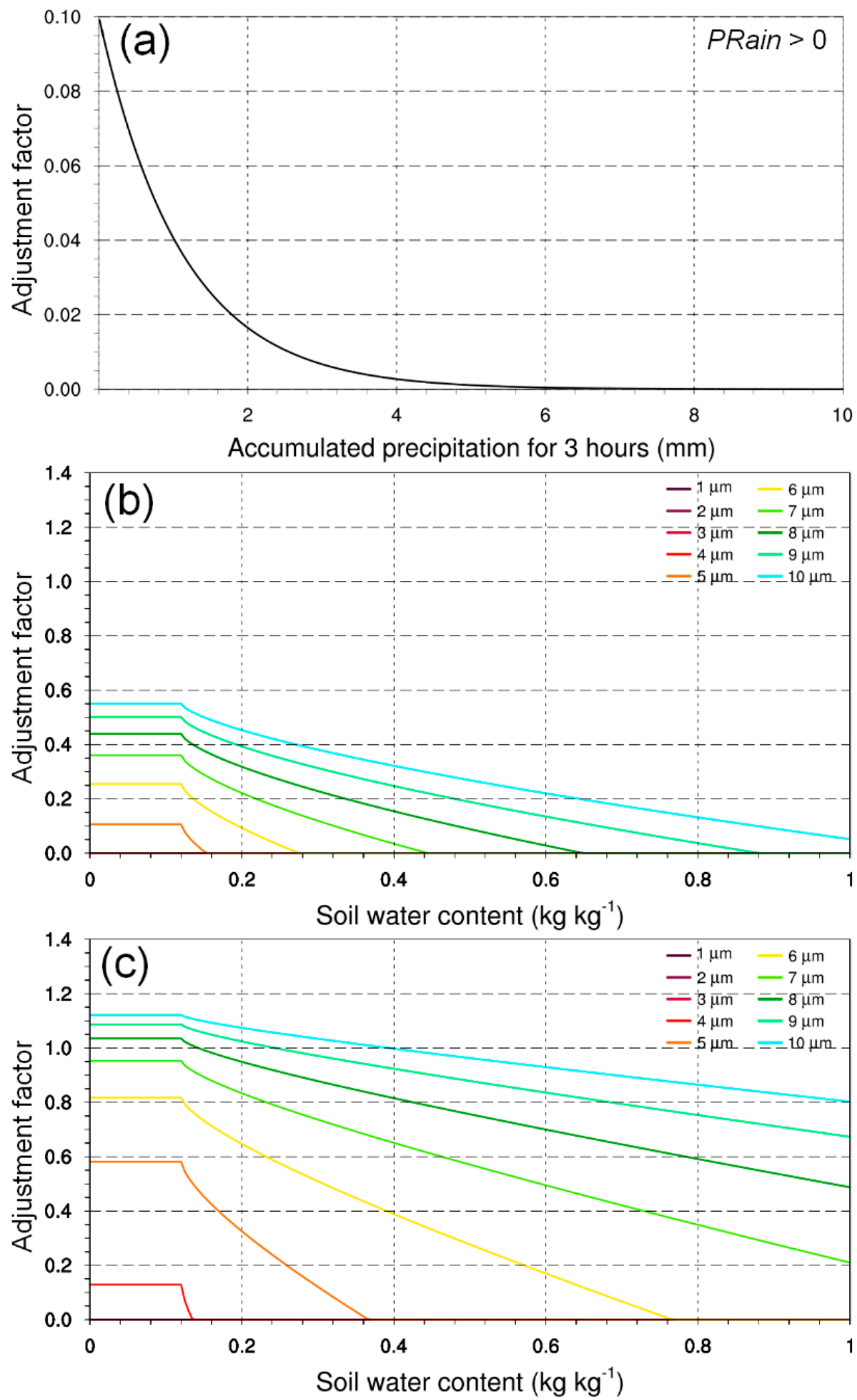

Figure 2. Example of the adjustment factor according to changes in (a) accumulated precipitation (PRain) over the 3-h period from 6 to $3 \mathrm{~h}$ prior to the emissions calculation in ADAM3_RAIN (PRain > 0), (b) the soil moisture content in ADAM3_SM1, and (c) ADAM3_SM2 (friction velocity $=0.8 \mathrm{~m} \mathrm{~s}^{-1}$, clay mass fraction $=0.5 \mathrm{~kg} \mathrm{~kg}^{-1}$ ). 


\subsection{ADAM3_SM1}

In ADAM3_SM1, surface-wetness effects in the adjustment factor $\left(H_{A D A M 3} S M 1\right.$ in Equation (7)) are specified by using the term $\left(1-\left(\frac{u_{* t}}{u_{*}}\right)^{2}\right)$ based on Owen [31] and Tanaka and Chiba [13]:

$$
H_{A D A M 3 \_S M 1}=\sum_{i=1}^{n}\left(1-f_{i} R_{i}\right) \times\left(1-\left(\frac{u_{* t}}{u_{*}}\right)^{2}\right) \times \alpha \times u^{* 4}, \text { if } u_{*} \geq u_{* t},
$$

where $u_{*}$ is the friction velocity and $u_{* t}$ is threshold friction velocity determined by the particle size and soil moisture), expressed as follows:

$$
u_{* t}=u_{* t, k, w}=u_{* t 0, k} f_{w, w},
$$

where $u_{* t 0}$ is the threshold friction velocity for $k$ [32], and $f_{w}$ is the effect of soil moisture on $u_{* \mathrm{u}}$, followed by the parameterization in the paper of Fécan et al. [33]:

$$
f_{w}=\left\{\begin{array}{cl}
1 & \text { if } \omega \leq \omega_{r} \\
\sqrt{1+1.21\left[100\left(\omega-\omega_{r}\right)\right]^{0.63},} & \text { if } \omega>\omega_{r},
\end{array}\right.
$$

where $\omega$ is the gravimetric soil water content, and $\omega_{r}$ is the threshold gravimetric soil water content can be calculated by using the mass fraction of clay $\left(M_{\text {clay }}\right)$ as follows:

$$
\omega_{r}=0.17 M_{\text {clay }}+0.14 M_{\text {clay }}^{2}
$$

In this study, the soil-moisture-content data were taken from the volumetric soil moisture content $\left(\mathrm{m}^{3} \mathrm{~m}^{-3}\right)$ in the Unified Model and was converted to the gravimetric soil water content $\left(\mathrm{kg} \mathrm{kg}^{-1}\right)$ following Zender et al. [34]. Moreover, the mass fraction in soil was obtained from the harmonized world soil database [35] for converting units of soil moisture content. Detailed information on the effect of soil moisture in ADAM3_SM1 can be found in Tanaka and Chiba [13].

\subsection{ADAM3_SM2}

In ADAM3_SM2, the adjustment factor term related to precipitation $\left(1+\frac{u_{* t}}{u_{*}}\right)\left(1-\left(\frac{u_{* t}}{u_{*}}\right)^{2}\right)$ considering the threshold friction velocity for soil particles in Gong et al. [14] is added to the CNTL, and the dust generation of ADAM3_SM2 ( $\left.H_{A D A M}{ }_{-} S M 2\right)$ can be expressed as follows:

$$
H_{A D A M 3 \_S M 2}=\sum_{i=1}^{n}\left(1-f_{i} R_{i}\right) \times\left(1+\frac{u_{* t}}{u_{*}}\right)\left(1-\left(\frac{u_{* t}}{u_{*}}\right)^{2}\right) \times \alpha \times u^{* 4}, \text { if } u_{*} \geq u_{* t},
$$

where $u_{* t}$ is the threshold friction velocity based on the roughness length parameterization suggested by Marticorena and Bergametti [23] and proportional to the soil moisture effect followed by the parameterization in the paper of Fécan et al. [33]. The condition for dust generation in ADAM3_SM2 $\left(u_{*} \geq u_{* t}\right)$ is the same as in ADAM3_SM1. Moreover, the soil-moisture-content data and the mass-fraction data of sand and clay in soil used the same data as in ADAM3_SM1. Detailed information the effect of soil moisture in ADAM3_SM2 can be found in the paper of Gong et al. [14].

Figure 2b,c show the adjustment factor of ADAM3_SM1, and ADAM3_SM2 according to the change in soil water content and particle size $(1 \sim 10 \mu \mathrm{m})$ when the friction velocity is $0.8 \mathrm{~m} \mathrm{~s}^{-1}$ and the clay mass fraction is $0.5 \mathrm{~kg} \mathrm{~kg}^{-1}$.

The factors are related to $u_{*}$ and soil moisture in the $u_{* t}$ term in the formulation of Tanaka and Chiba [13] and Gong et al. [14]. Hence, the adjustment factor is applied to all cases, both precipitating and non-precipitating. In Figure $2 b, c$, the adjustment factors in ADAM3_SM1 and ADAM3_SM2 decrease as soil moisture increases and the particle size decreases; the larger the particle, the higher the factor for the same soil moisture. In the dry cases $\left(\omega \leq \omega_{r}\right)$, the adjustment factor is determined irrespective of soil moisture. For this reason, the factor shows as constant in dry case (soil water content $\leq 0.14 \mathrm{~kg} \mathrm{~kg}^{-1}$ ) 
(Figure $2 \mathrm{~b}, \mathrm{c}$ ). Moreover, the adjustment factor $>1$ occurs when $u_{*}$ is very strong, only in ADAM3_SM2 (Figure 2c). The ADAM3_SM2 adjustment factors show larger than the ADAM3_SM1 adjustment factor for the same particle size.

\section{Results and Discussion}

\subsection{Characteristics of the Frequency of Dust Occurrence Based on Past Precipitation}

Figure 3 shows the relative frequency (frequency by the range/number of precipitation cases or non-precipitation cases) for the distribution of the $\mathrm{PM}_{10}$ mass concentration from the $\mathrm{PM}_{10}$ data observed at $15 \mathrm{KMA}-\mathrm{CMA}$ joint monitoring stations from 2004 to 2019 . The precipitation (rain) cases were defined as a 3-h accumulative precipitation event exceeding $1 \mathrm{~mm}$ and a wind speed exceeding $7.5 \mathrm{~m} \mathrm{~s}^{-1}$, which is the maximum threshold wind speed in spring (March-May) for dust generation presented in Table 2 of the study by Park et al. [10]. When wind speed exceeds the threshold value with no precipitation, this is categorized as a non-precipitation (no-rain) case.

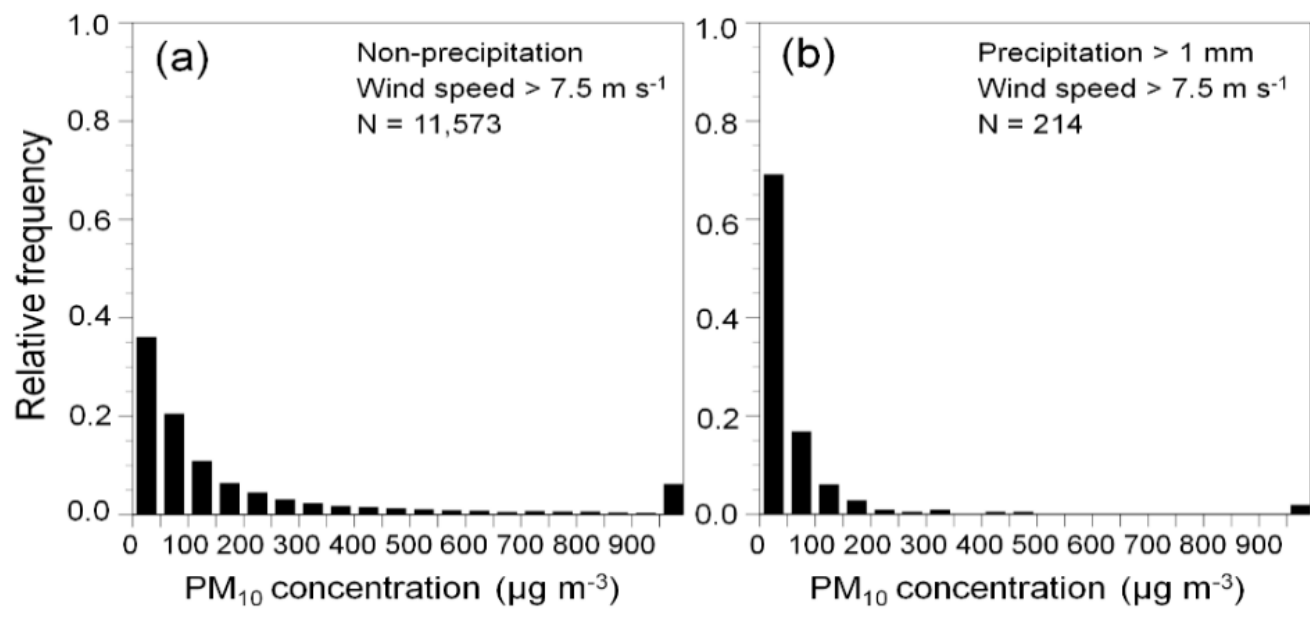

Figure 3. Relative frequency of 3-hourly $\mathrm{PM}_{10}$ mass concentration observed at $15 \mathrm{KMA}-\mathrm{CMA}$ joint monitoring stations from 2004 to 2019 for (a) no-rain and (b) rain cases. The no-rain case is defined as when $U_{10}$ exceeds $7.5 \mathrm{~m} \mathrm{~s}^{-1}$ with no precipitation, and the rain case is defined as when 3-h accumulative precipitation exceeds $1 \mathrm{~mm}$ and $U_{10}$ exceeds $7.5 \mathrm{~m} \mathrm{~s}^{-1}$.

The observed $\mathrm{PM}_{10}$ mass concentration for the no-rain cases shows high frequencies in the range below $150 \mathrm{\mu g} \mathrm{m}^{-3}$, with few instances (less than 0.01) in the range above $300 \mu \mathrm{g} \mathrm{m}^{-3}$. In rain cases, the relative frequency of the observed $\mathrm{PM}_{10}$ mass concentration was larger in the range below $100 \mu \mathrm{g} \mathrm{m}^{-3}$ and smaller in the range above $100 \mu \mathrm{g} \mathrm{m}^{-3}$ than that in no-rain cases. This result indicates that generation of dusts in East Asia suppressed when precipitation occurs at the source regions and that there are fewer cases of high concentration dust events.

To investigate whether all runs effectively simulate the observed characteristics, Figure 4 shows the relative frequency distribution of the predicted $\mathrm{PM}_{10}$ mass concentration in CNTL, ADAM3_RAIN, ADAM3_SM1, and ADAM3_SM2 for the no-rain and rain cases. 

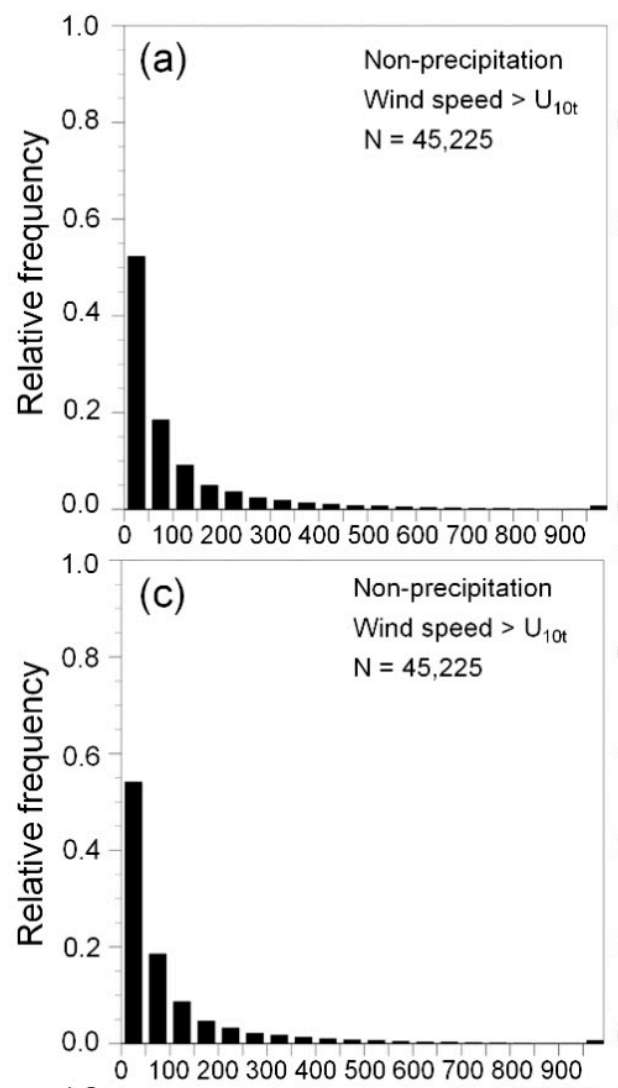

0100200300400500600700800900 1.0

(d) Precipitation $>1 \mathrm{~mm}$ $0.8 \quad$ Wind speed $>U_{10 t}$
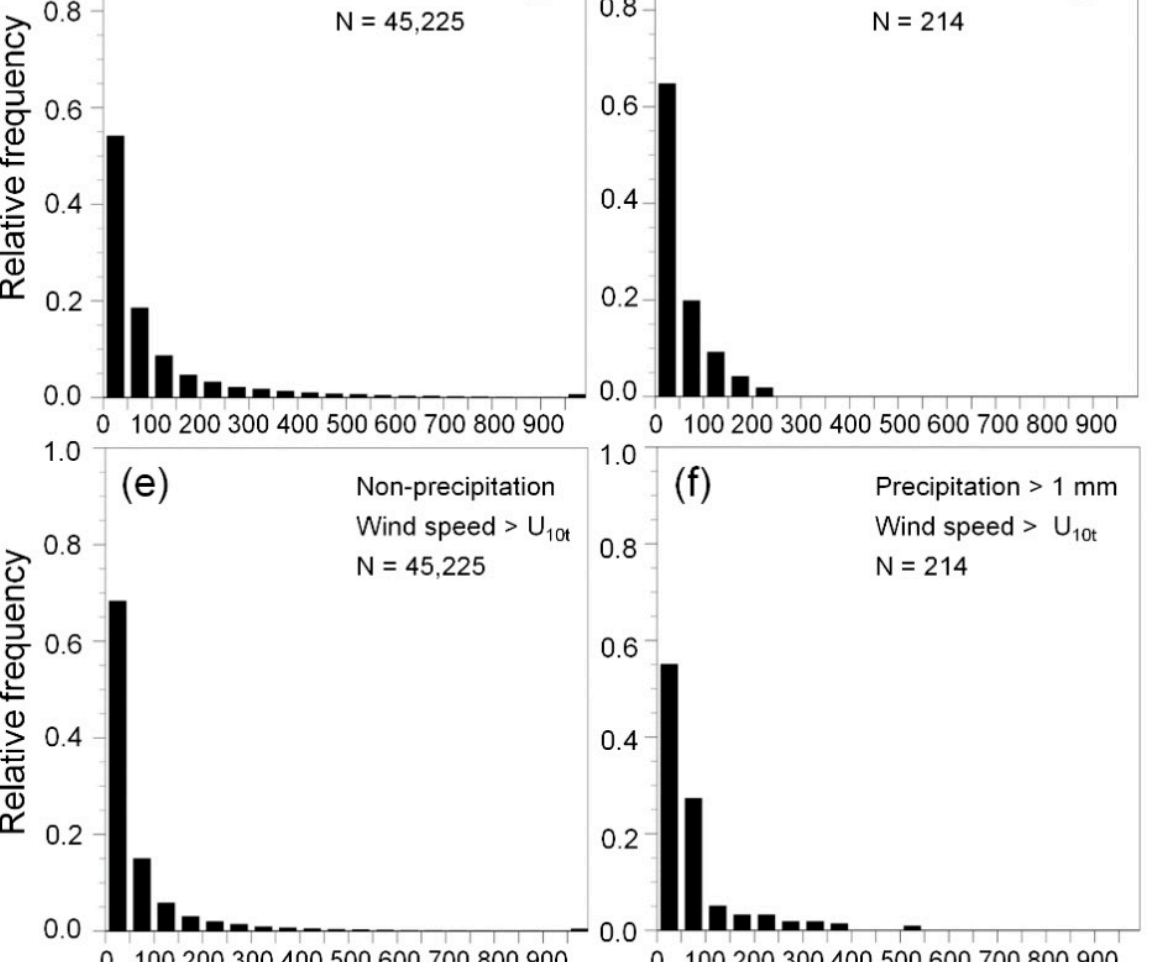

(f)

Precipitation $>1 \mathrm{~mm}$ $0.8-\quad N=214$ Wind speed $>U_{10 t}$ 1.0

(g) Non-precipitation

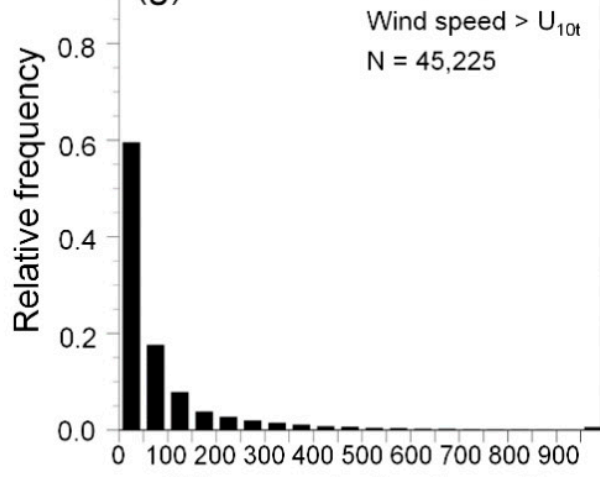
$\mathrm{PM}_{10}$ concentration $\left(\mu \mathrm{g} \mathrm{m}^{-3}\right)$

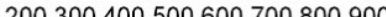

(h)

Precipitation $>1 \mathrm{~mm}$ Wind speed $>U_{10 t}$ $0.8-\quad N=214$

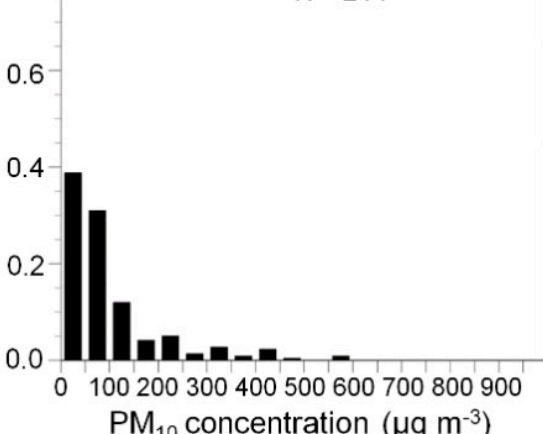

Figure 4. Relative frequency for $\mathrm{PM}_{10}$ mass concentrations simulated by $(\mathbf{a}, \mathbf{b})$ CNTL run, $(\mathbf{c}, \mathbf{d})$ ADAM3_RAIN run, (e,f) ADAM3_SM1 run, and (g,h) ADAM3_SM2 run for (left) no-rain and (right) rain cases from March to May 2020. 
In no-rain cases, the frequency distribution in CNTL is similar to the observation, but the CNTL run overestimates the observed frequency in the range above $150 \mathrm{\mu g} \mathrm{m}^{-3}$ for the rain cases. In the rain cases, the ADAM3_RAIN run with the precipitation effects show that the frequencies decrease from CNTL in the range above $150 \mu \mathrm{g} \mathrm{m}^{-3}$ and did not appear in the range exceeding $300 \mathrm{~m}^{-3}$, and that the frequency distributions become closer to the observations than CNTL (no surface-wetness effects). The ADAM3_SM2 show that the frequencies decrease in the range below $50 \mu \mathrm{g} \mathrm{m}^{-3}$ and increase in the range 50 100 $\mu \mathrm{g} \mathrm{m}^{-3}$ compared to CNTL. Particularly, the frequency in both ADAM3_SM1 and ADAM3_SM2 did not appear in the range exceeding $600 \mu \mathrm{g} \mathrm{m}^{-3}$ because the wetter the soil surface the harder the lifting of soil particles from the surface, so that the frequency distribution in the high $\mathrm{PM}_{10}$ concentration range is similar to the observation compared to CNTL.

These results show that runs with surface-wetness effects suppress the amount of dust generation in East Asia in the high $\mathrm{PM}_{10}$ concentration range by considering the surface-wetness effects on dust generation.

\subsection{Evaluation for Spring Time}

The simulations were evaluated by using the hourly $\mathrm{PM}_{10}$ mass concentration data observed at 1498 MEP sites in the Regions B, C, and D from March to May 2020. Table 2 shows the RMSEs of CNTL, ADAM3_RAIN, ADAM3_SM1, and ADAM3_SM2 for the $\mathrm{PM}_{10}$ mass concentration. Moreover, Table 1 shows the SSs of the three runs with surfacewetness effects (ADAM3_RAIN, ADAM3_SM1, and ADAM3_SM2) to measure changes in the forecast performance by including the surface-wetness effects relative to the RMSE of CNTL.

In Table 1, wet and dry cases were classified by using the 24-h accumulated precipitation at the grid point of the Unified Model closest to each GTS site because measurement of precipitation is not conducted in MEP sites. If the 24-h accumulated precipitation occurred in more than $50 \%$ of the grid points of the analysis area, it was defined as a wet case. Moreover, because only few wet cases exist for the entire dust source regions in East Asia, wet and dry cases were considered in only Regions $\mathrm{C}$ and D.

RMSEs of CNTL showed 90.22 for all cases, 73.65 for wet cases, and 64.19 for dry cases. The three runs that include either the precipitation or soil moisture to represent the surface-wetness effects show smaller RMSEs compared to the CNTL and positive SSs. Specifically, ADAM3_SM1 yields the best performance among all runs with RMSE of 79.53 and SS of 12.51. Moreover, RMSEs in ADAM3_SM2 and ADAM3_RAIN are reduced for all cases (80.36 and 86.43 , respectively) compared to CNTL (90.22). The three runs with either precipitation effects or moisture effects yield larger SS values in the wet cases than in the dry cases. Specifically, the SSs of ADAM3_SM1 show approximately twice as large as in the wet cases (17.53) than in the dry cases (8.15), i.e., much larger improvements for the wet cases. The adjustment factor in ADAM3_SM1 and ADAM3_SM2 (Figure 2), which account for the surface-wetness effects more directly by using soil moisture, is applied to all cases, not only to precipitation cases, in which condition is met. Moreover, there could be sites where precipitation occurred during a dry case since it is defined as a dry case when the accumulated precipitation is less than $50 \%$ of the grid points of the Regions $C$ and D. Moreover, the wind effect in the dust-generation algorithm in all runs is not the same. For this reason, dust generation in the dry cases are not the same and RMSEs in dry cases could be improved.

Hourly data from 1498 MEP stations during the spring of 2020 are used to evaluate the EXPR (ADAM3_RAIN, ADAM3_SM1, and ADAM3_SM2) experiments. In addition to RMSE, a binomial probability analysis was used to evaluate the model performance. The success counts for Regions B, C, and D are 87, 77, and 81, respectively, for ADAM3_RAIN; 88, 82, and 81, respectively, for ADAM3_SM2; and 92, 92, and 90, respectively, for ADAM3_SM1. From these results, it is assumed that the success probability of CTRL and EXPR experiments are equal to 0.5, and the probability that ADAM3_RAIN, 
which has the lowest number of successes, will come out with 77, the number of successes probability in area $C$, is $1.3 \times 10^{-11}$. This number can be interpreted as a result of rejecting the hypothesis that the CNTL and EXPR success rates are the same at the significance level of 0.01. Therefore, the success rates are higher for EXPR than CNTL, suggesting that inclusion of the surface-wetness effects on dust generation has improved dust forecasts in East Asia.

MBEs of all runs in spring 2020 are shown in Table 3. The CNTL run overestimates the $\mathrm{PM}_{10}$ mass concentration with positive MBE for all three cases with largest (smallest) MBEs in the wet (dry) cases. The three runs with surface-wetness effects (i.e., ADAM3_RAIN, ADAM3_SM1, and ADAM3_SM2) yield smaller MBEs than CNTL. Note negative MBEs in the dry cases. Specifically, the reduction rates of $\mathrm{MBE}$ are larger in the wet cases than in the dry cases. Moreover, ADAM3_SM1 reduces the overestimation of $\mathrm{PM}_{10}$ mass concentration in CNTL. ADAM3_SM1 shows the smallest MBE among all cases, but the $\mathrm{MBE}$ in the dry cases increases as the MBE in CNTL is negative. The adjustment factor decreases as increased precipitation and soil moisture in ADAM3_RAIN, ADAM3_SM1, and ADAM3_SM2 (Figure 2), respectively, so that the dust generation decreased and it might lead to improve MBEs and RMSEs in the wet cases.

Table 3. MBE for CNTL, ADAM3_RAIN, ADAM3_SM1, and ADAM3_SM2. The evaluation period was set for the spring season from March to May 2020. All represents total cases for Regions B, C, and D, whereas wet and dry denote precipitation and non-precipitation cases for Regions B and C, respectively. The total number of forecasts (n) is 1,102,528.

\begin{tabular}{ccccc}
\hline Case & CNTL & ADAM3_RAIN & ADAM3_SM1 & ADAM3_SM2 \\
\hline All & 10.16 & 3.79 & 1.32 & 5.47 \\
Wet & 15.95 & 9.61 & 1.45 & 6.14 \\
Dry & 2.77 & -0.56 & -4.98 & -0.93 \\
\hline
\end{tabular}

Reduced dust generation caused by either the precipitation or soil moisture effects yields smaller MBEs in the regions of large positive MBEs (i.e., improved dust generation calculations) but further increases negative MBEs in the regions where CNTL underestimates dust generation (i.e., degraded dust-generation calculations) such as for the dry cases in ADAM3_SM1. As shown in Figure 4, the overall RMSE is likely reduced because relative frequency in the high concentration range $\left(300 \mu \mathrm{g} \mathrm{m}^{-3}\right.$ or more) is substantially reduced by the surface-wetness effect. Fécan et al. [33] shows that soil moisture content that varies with precipitation increases the cohesion among soil particles, resulting in a larger threshold friction velocity for lifting soil particles. This can explain the reduction in dust generation in ADAM3_SM1 and ADAM3_SM2. The difference in the MBE reductions between ADAM3_SM1 and ADAM3_SM2 due to the surface-wetness effects can be explained as the difference in the reduction factor term related to precipitation in Figure $2 b, c$. The amount of $\mathrm{PM}_{10}$ mass concentration was suppressed more in ADAM3_SM1 than in ADAM3_SM2 due to a higher reduction factor in the same the soil moisture content (Figure 2b,c).

Uncertainties are noted in the surface-wetness effects on dust generation estimated in this study. This study used the precipitation at the grid point of the Unified Model (UM) closest to each GTS for the classification of wet and dry cases. The potential mismatch in the locations of the UM grids and the GTS stations can introduce uncertainties in the definition of "wet" and "dry" cases. In addition, the portion of local dust generation cannot be separated from the portion of long-range transport in the observed dust concentration. This can be another source of uncertainties in the effects of surface wetness on dust generation obtained in this study.

The simulated $\mathrm{PM}_{10}$ mass concentration was investigated for 20 April 2020, a wet case in which dusts in East Asia were substantially overestimated over Manchuria. Figure 5 shows the horizontal distribution of the $\mathrm{PM}_{10}$ mass concentration in CNTL and the differences in $\mathrm{PM}_{10}$ mass concentrations from CNTL due to the inclusion of surface-wetness effects at 12 UTC on 20 April 2020. The PM 10 mass concentration in CNTL exceeds the 
observed value (below $100 \mu \mathrm{g} \mathrm{m}^{-3}$ ) by approximately $200-300 \mu \mathrm{g} \mathrm{m}^{-3}$ in Manchuria (Figure 5a). All three runs (ADAM3_RAIN, ADAM3_SM1 and ADAM3_SM2) generate smaller $\mathrm{PM}_{10}$ mass concentration than CNTL. The decrease in the $\mathrm{PM}_{10}$ mass concentration due to surface-wetness effects is most notable in the Gobi Desert and Manchuria in all runs.

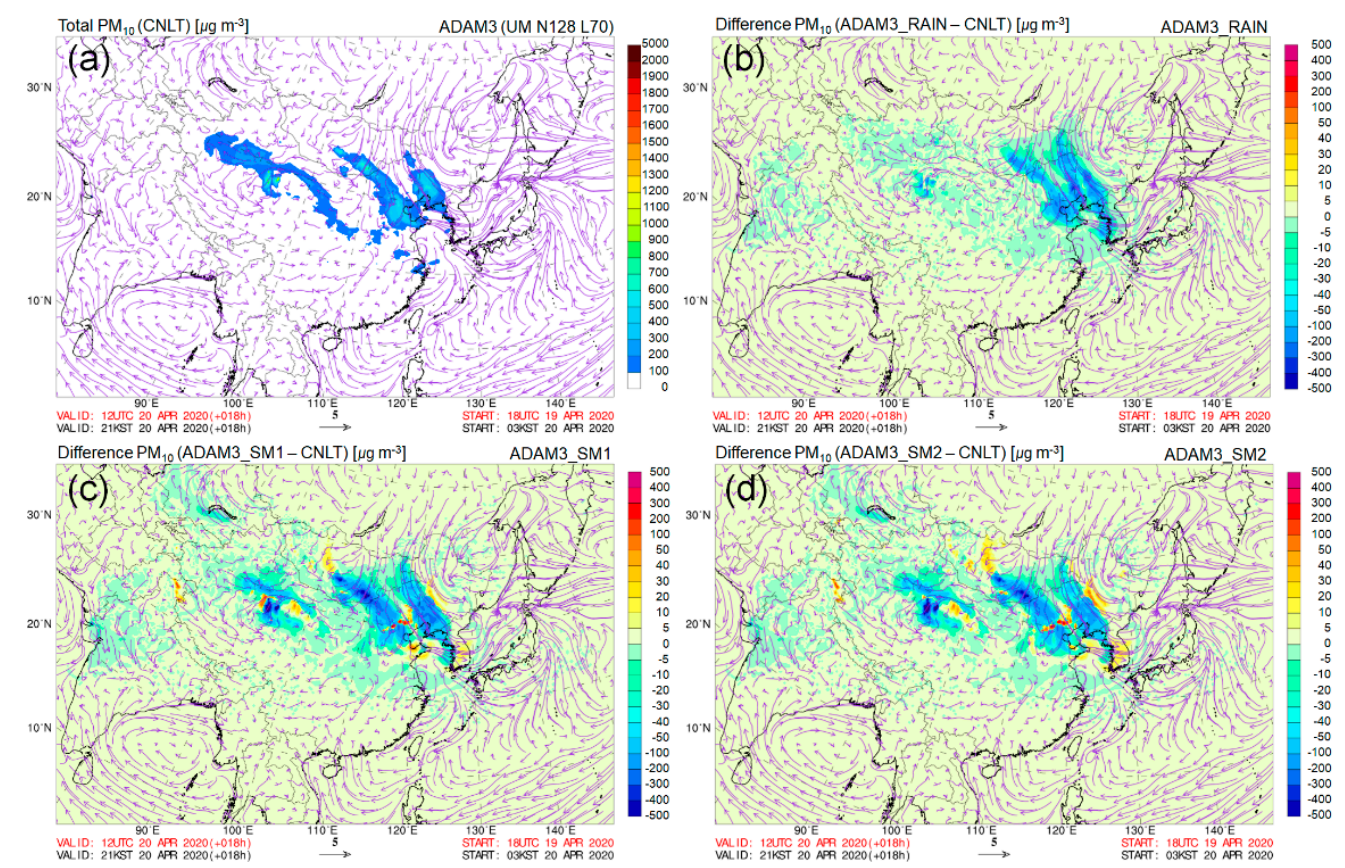

Figure 5. (a) Horizontal distribution of $\mathrm{PM}_{10}$ mass concentration in CNTL and horizontal distribution of $\mathrm{PM}_{10}$ mass concentration differences between CNTL and the three runs with surface-wetness effects: (b) ADAM3_RAIN, (c) ADAM3_SM1, and (d) ADAM3_SM2; these distributions were all taken on 20 April 2020, 12 UTC.

Regionally, ADM3_SM1 and ADAM3_SM2 reduce most the excessive dust concentrations in Manchuria, but increased the $\mathrm{PM}_{10}$ mass concentration at Bohai Bay.

The differences in $\mathrm{PM}_{10}$ mass concentrations among the three runs might be related to the differences in the representation of the wind effects on dust generation as ADAM3_RAIN employs $U_{10}$ while ADM3_SM1 and ADAM3_SM2 use $u_{* t}$ (Table 2).

ADAM3_RAIN reduces the amount of dust generation unconditionally during precipitation based on 3-h accumulated precipitation if $U_{10}$ exceeds $U_{10 t}$. However, the $\mathrm{PM}_{10}$ mass concentration in ADAM3_SM1 and ADAM3_SM2 might increase due to $u_{* t}$ which also depends on soil moisture.

Figure 6 shows the time series of the observed and simulated average $\mathrm{PM}_{10}$ mass concentrations in the Region D on 20 April 2020. The observation shows the first peak of the concentration with less than $100 \mu \mathrm{g} \mathrm{m}^{-3}$ on the 20th at 12 UTC and second peak of the concentration with approximately $220 \mu \mathrm{g} \mathrm{m}^{-3}$ on the 21st at 08UTC. All runs overestimate the $\mathrm{PM}_{10}$ mass concentration at the observed peak time. The CNTL run shows the highest $\mathrm{PM}_{10}$ mass concentration among all runs, and ADAM3_RAIN, ADAM3_SM1, and ADAM3_SM2 run simulate PM $_{10}$ mass concentration lower than CNTL. Specifically, the $\mathrm{PM}_{10}$ mass concentration in ADAM3_RAIN is closest to the observation among all runs, but the peak time of the $\mathrm{PM}_{10}$ mass concentration is not accurately simulated due to excessive reduction of the peak concentration on the 21st. ADAM3_SM1 and ADAM3_SM2 show smaller effects of precipitation on reducing PM $_{10}$ mass concentration as ADAM3_RAIN, but the timing of highest concentration compares well with the observation. 


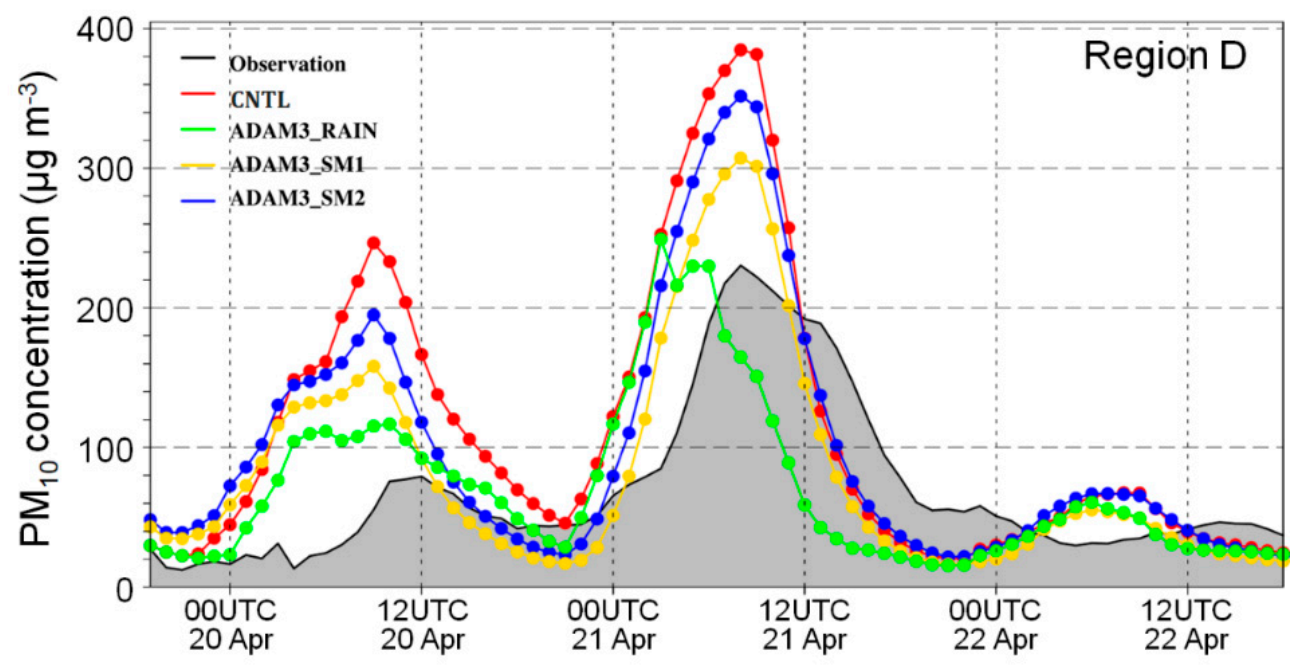

Figure 6. Time series of $\mathrm{PM}_{10}$ mass concentrations in Region D, from 20 to 22 April 2020. The gray area represents observations, and the red dots denote the results of CNTL.

\section{Summary and Conclusions}

ADAM3 is one of the dust forecast models in the WMO SDS-WAS Asian Node. The ADAM3 often tends to overestimate dust generation in the dust source regions in East Asia under precipitating conditions. This study examined the effects of incorporating surface-wetness effects on dust generation in ADAM3 over the dust source regions of East Asia in a model sensitivity experiment in which four ADAM3 model versions with various representation of the surface-wetness effects on dust generation are employed.

Evaluation of the simulated dust concentrations against the observations, using RMSE and SS as the performance metrics, show that the incorporation of surface-wetness effects, precipitation, and soil moisture significantly reduces overall MBE compared to CNTL. Particularly, ADAM3_SM1, which considered the effects of soil moisture on dust generation, yields the best performance in predicting the $\mathrm{PM}_{10}$ mass concentration over the dust source regions in East Asia. It is also found that the improvements in dust generation vary according to regions. The increase in the negative MBE in the region where ADAM3 underestimates dust generation (i.e., the small positive MBE in ADAM3 became increasingly negative through the incorporation of the surface-wetness effects) suggests that the ADAM3 errors originate not only from the lack of precipitation (or soil moisture) effects on dust generation but also from other model deficiencies.

This study shows that the incorporation of surface-wetness effects on dust generation into the ADAM3 model can improve dust prediction over the dust source regions in East Asia that affect South Korea most.

It is important to note that this study has several limitations. In this study, quantification of the wind-only effects cannot be performed within the context of the formulations employed to represent the surface-wetness effects on dust generation. Because the wind effect term is an integral part of each formulation, it cannot be separated from each formulation. Thus, the wind terms in different formations are not interchangeable, and this makes the sensitivity experiment for quantifying the wind-only effects unavailable.

Moreover, Region A, which is an area substantially underestimated in ADAM3, was excluded from the evaluation in this study. Ryoo et al. [12] and Hong et al. [25] traced that one of the causes of the systematic underestimation in Region A is lack of information at the lateral boundaries. This needs to be resolved in future research with additional dust data from large-scale forecast models. 
Author Contributions: Conceptualization, J.K. and Y.L.; methodology, Y.L. and M.K.; software, Y.L. and M.K.; validation, Y.L. and M.K.; formal analysis, Y.L.; investigation, M.K. and Y.L.; data curation, M.K. and Y.L.; writing-original draft preparation, Y.L.; writing—review and editing, J.K., Y.L., and M.K.; visualization, Y.L. and M.K.; supervision, Y.L. All authors have read and agreed to the published version of the manuscript.

Funding: This work was funded by the Korea Meteorological Administration Research and Development Program "Development of Asian Dust and Haze Monitoring and Prediction Technology" under Grant No. KMA2018-00521 and "Development and Assessment of Climate Change Scenario" under Grant No. KMA2018-00321.

Institutional Review Board Statement: Not applicable.

Informed Consent Statement: Not applicable.

Data Availability Statement: Not applicable.

Acknowledgments: The authors would like to give thanks to two reviewers for useful suggestions and comments.

Conflicts of Interest: The authors declare no conflict of interest.

\section{References}

1. Ding, Y.H.; Lin, Y.J. Analysis of long-term variations of fog and haze in China in recent 50 years and their relations with atmospheric humidity. Sci. China Earth Sci. 2014, 57, 36-46. [CrossRef]

2. Wang, H.J.; Chen, H.P. Understanding the recent trend of haze pollution in eastern China: Roles of climate change. Atmos. Chem. Phys. 2016, 16, 4205-4211. [CrossRef]

3. Lee, S.; Ho, C.H.; Choi, Y.S. High-PM $\mathrm{PM}_{10}$ concentration episodes in Seoul, Korea: Background sources and related meteorological conditions. Atmos. Environ. 2011, 45, 7240-7247. [CrossRef]

4. Oh, H.R.; Ho, C.H.; Kim, J.; Chen, D.; Lee, S.; Choi, Y.S.; Chang, L.S.; Song, C.K. Long-range transport of air pollutants originating in China: A possible major cause of multi-day high- $\mathrm{PM}_{10}$ episodes during cold season in Seoul, Korea. Atmos. Environ. 2015, 109, 23-30. [CrossRef]

5. Watanabe, M.; Yamasaki, A.; Burioka, N.; Kurai, J.; Yoneda, K.; Yoshida, A.; Igishi, T.; Fukuoka, Y.; Nakamoto, M.; Takeuchi, H. Correlation between Asian dust storms and worsening asthma in western Japan. Allergol. Int. 2011, 60, 267-275. [CrossRef]

6. Tam, W.W.; Wong, T.W.; Wong, A.H.; Hui, D.S. Effect of dust storm events on daily emergency admissions for respiratory diseases. Respirology 2012, 17, 143-148. [CrossRef]

7. Lee, H.; Kim, H.; Honda, Y.; Lim, Y.H.; Yi, S. Effect of Asian dust storms on daily mortality in seven metropolitan cities of Korea. Atmos. Environ. 2013, 79, 510-517. [CrossRef]

8. Shepherd, G.; Terradellas, E.; Baklanov, A.; Kang, U.; Sprigg, W.; Nickovic, S.; Boloorani, A.D.; Al-Dousari, A.; Basart, S.; Benedetti, A.; et al. Global Assessment of Sand and Dust Storms; United Nations Environment Programme: Nairobi, Kenya, 2016 ; p. 123. ISBN 978-92-807-3551-2.

9. Park, S.U.; In, H.J. Parameterization of dust emission for the simulation of the yellow sand (Asian dust) event observed in March 2002 in Korea. J. Geophys. Res. Atmos. 2003, 108, 1-21. [CrossRef]

10. Park, S.U.; Choe, A.; Lee, E.H.; Park, M.S.; Song, X. The Asian dust aerosol model 2 (ADAM2) with the use of normalized difference vegetation index (NDVI) obtained from the Spot4/vegetation data. Theor. Appl. Climatol. 2010, 101, 191-208. [CrossRef]

11. Park, S.U.; Cho, J.H.; Park, M.S. A simulation of aerosols in Asia with the use of ADAM2 and CMAQ. Adv. Fluid Mech. Heat Mass Transf. 2012, 258-263.

12. Ryoo, S.B.; Kim, J.; Cho, J.H. Performance of KMA-ADAM3 in identifying Asian dust days over Northern China. Atmosphere 2020, 11, 593. [CrossRef]

13. Tanaka, T.Y.; Chiba, M. Global simulation of dust aerosol with a chemical transport model, MASINGAR. J. Meteorol. Soc. Jpn. 2005, 83, 255-278. [CrossRef]

14. Gong, S.L.; Zhang, X.Y.; Zhao, T.L.; McKendry, I.G.; Jaffe, D.A.; Lu, N.M. Characterization of soil dust aerosol in China and its transport and distribution during 2001 ACE-Asia: 2. Model simulation and validation. J. Geophys. Res. 2003, 108, 4262. [CrossRef]

15. Gong, S.L.; Zhang, X.Y. CUACE/Dust-An integrated system of observation and modeling systems for operational dust forecasting in Asia. Atmos. Chem. Phys. 2008, 8, 2333-2340. [CrossRef]

16. Husar, R.B.; Tratt, D.M.; Schichtel, B.A.; Falke, S.R.; Li, F.; Jaffe, D.; Gassó, S.; Gill, T.; Laulainen, N.S.; Lu, F.; et al. Asian dust events of April 1998. J. Geophys. Res. 2001, 106, 18317-18330. [CrossRef]

17. Prospero, J.M.; Ginoux, P.; Torres, O.; Nicholson, S.E.; Gill, T.E. Environmental Characterization of Global Sources of Atmospheric Soil Dust Identified with the NIMBUS 7 Total Ozone Mapping Spectrometer (TOMS) Absorbing Aerosol Product. Rev. Geophys. 2002, 40, 2-1-2-31. [CrossRef]

18. Chung, Y.S.; Kim, T.K. On Long Range transport of air pollutants-sources and observations of yellow sand, TSP and sulphate in Korea. J. Korean Soc. Atmos. Environ. 1991, 7, 197-202. (In Korean) 
19. Chun, Y.; Boo, K.O.; Kim, J.; Park, S.U.; Lee, M. Synopsis, transport, and physical characteristics of Asian dust in Korea. J. Geophys. Res. Atmos. 2001, 106, 18461-18469. [CrossRef]

20. Chun, Y.; Cho, K.S.; Kim, Y.H.; Lee, J.K. The features of Asian dust events originated in Keoeolchin sandy land. Asia Pac. J. Atmos. Sci. 2003, 39, 251-263. (In Korean)

21. Kim, S.; Chun, Y.; Kim, S.B. The features of Asian dust events originated in Manchuria. Atmosphere 2010, 20, 273-286. (In Korean)

22. Marticorena, B.; Bergametti, G.; Aumont, B.; Callot, Y.; N’Doumé, C.; Legrand, M. Modeling the atmospheric dust cycle: 2. Simulation of Saharan dust sources. J. Geophys. Res. 1997, 102, 4387-4404. [CrossRef]

23. Marticorena, B.; Bergametti, G. Modeling the atmospheric dust cycle: 1. Design of a soil-derived dust emission scheme. J. Geophys. Res. 1995, 100, 16415-16430. [CrossRef]

24. Tegen, I.; Fung, I. Modeling of mineral dust in the atmosphere: Sources, transport, and optical thickness. J. Geophys. Res. 1994, 99, 22897-22914. [CrossRef]

25. Hong, S.K.; Ryoo, S.-B.; Kim, J.; Lee, S.-S. Prediction of Asian dust days over Northern China using the KMA-ADAM2 Model. Weather. Forecast. 2019, 34, 1777-1787. [CrossRef]

26. Lee, S.S.; Lim, Y.-K.; Cho, J.H.; Lee, H.C.; Ryoo, S.-B. Improved dust emission reduction factor in the ADAM2 model using real-time MODIS NDVI. Atmosphere 2019, 10, 702. [CrossRef]

27. Davies, T.; Cullen, M.J.P.; Malcolm, A.J.; Mawson, M.H.; Staniforth, A.; White, A.A.; Wood, N. A new dynamical core for the Met Office's global and regional modelling of the atmosphere. Q. J. R. Meteorol. Soc. 2005, 131, 1759-1782. [CrossRef]

28. Guenther, A.; Karl, T.; Harley, P.; Wiedinmyer, C.; Palmer, P.I.; Geron, C. Estimates of global terrestrial isoprene emissions using MEGAN (Model of Emissions of Gases and Aerosols from Nature). Atmos. Chem. Phys. 2006, 6, 3181-3210. [CrossRef]

29. Youngsin, C.; Lim, J.Y. The recent characteristics of Asian dust and haze events in Seoul, Korea. Meteorol. Atmos. Phys. 2004, 87, 143-152. [CrossRef]

30. Wilks, D.S. Statistical Methods in Atmospheric Sciences; Academic Press: San Diego, CA, USA, 1995; p. 255.

31. Owen, P.R. Saltation of uniform grains in air. J. Fluid Mech. 1964, 20, 225-242. [CrossRef]

32. Shao, Y.; Lu, H. A simple expression for wind erosion threshold friction velocity. J. Geophys. Res. 2000, 105, 22437-22443. [CrossRef]

33. Fécan, F.; Marticorena, B.; Bergametti, G. Parameterization of the increase of the aeolian erosion threshold wind friction velocity due to soil moisture for arid and semi-arid areas. Ann. Geophys. 1999, 17, 149-157. [CrossRef]

34. Zender, C.S.; Bian, H.; Newman, D. Mineral Dust Entrainment and Deposition (DEAD) model: Description and 1990s dust climatology. J. Geophys. Res. 2003, 108, 4416. [CrossRef]

35. Nachtergaele, F.; Van Velthuizen, H.; Verelst, L.; Wiberg, D. Harmonized World Soil Database Version 1.2; FAO: Rome, Italy; IIASA: Laxenburg, Austria, 2012. 